\title{
EDUCACIÓN EMOCIONAL EN EL PROCESO DE FORMACIÓN DOCENTE
}

Javier Sánchez Córdoba, Fco. Javier Pérez Domínguez y Antonio J. Venegas Garrido

\section{Universidad de Huelva. Email: antoniojose.venegas@alu.uhu.es}

RESUMEN: En esta comunicación procedemos a revisar el estado actual de la educación emocional en el proceso de la formación docente, así como su relevancia en la sociedad actual. Esta visión nos ofrece un enfoque mucho más amplio de la inteligencia humana y un nuevo salto al tratamiento educativo sobre la enseñanza de la educación emocional.

PALABRAS CLAVE: Educación emocional, formación docente, inteligencia emocional 


\section{1.- INTRODUCCIÓN}

A raíz de los trabajos de Salovey y Mayer (1990) y Gadner $(1995,2001)$ sobre las inteligencias múltiples, y de sus seguidores Goleman, (1995, entre otros) la investigación educativa se interesa especialmente por las emociones y su especial relevancia en la sociedad del futuro.

La educación emocional ha de entenderse como un factor importante en el desarrollo de la personalidad del individuo, dado que cuando se potencia y gestionan los recursos emocionales se mejora la calidad de vida (Bisquerra ,2000). Sus aplicaciones han demostrado que reforzar las habilidades de socialización (respeto, autoestima, asertividad, empatía) entre el alumnado y la inteligencia emocional de los profesores mejora la convivencia en las aulas y previene el fracaso escolar, el bullying, la homofobia, las relaciones de pareja dominantes y hasta el consumo de drogas Costa, M. (2002). Es más, sin un clima normalizado en el aula, difícilmente se imparten los contenidos del currículum educativo, explica Joana Ferrer coordinadora pedagógica del centro Júlia Minguell en Catalunya. En un artículo titulado "Para poder edificar, necesitamos primero allanar el terreno".

Por lo que ahora es el momento ideal para incorporar en todos los niveles de enseñanza formal, a la Educación Emocional como materia obligatoria y de aplicación universal Beltrán (1996; 401). Cuanto más popular sea la idea, mayor será el interés que se genere alrededor de la misma por parte de quienes deciden en estas cuestiones, es por esto que nuestro mayor aporte será, manifestar nuestra opinión basadas en investigaciones y experiencias extraídas de Dialnet, planteando esta problemática a los nuevos docentes, directores de los centros, a nuestros familiares y amigos, puesto que el conocimiento y las emociones son características de todos nosotros y que tienen lugar constantemente en cualquier situación.

Jamás debemos olvidar que el alumno aprende con el profesor, además de aprender de él (curriculum oculto); transformándose el docente en un modelo potencial de un adulto, ya que la acción del profesor en el aula y fuera de ella es un elemento importante Fernández-Berrocal y Ramos, (2002). Así en el contexto escolar como subraya Fernández-Berrocal y Extremera $(2004 ; 6)$ "los educadores son los principales líderes emocionales de sus alumnos 
Sala, J. (2002) Diversos argumentos justifican la necesidad que demanda la sociedad actual en la que la inteligencia emocional es la base para una evolución en todos los ámbitos de la persona.

1. La finalidad de la educación es el pleno desarrollo de la personalidad integral del alumnado. En este desarrollo pueden distinguirse al menos dos aspectos importantes: el desarrollo cognitivo y el desarrollo emocional, dándole más importancia al segundo.

2. La educación es un proceso caracterizado por la relación interpersonal y toda relación entre personas está caracterizado por fenómenos emocionales. Ello exige que se le preste una atención especial por la enorme influencia que ejercen las emociones sobre los procesos de aprendizaje.

3. El autoconocimiento, "Conócete a ti mismo", que fue el lema de Sócrates, y desde entonces ha sido uno de los objetivos del ser humano. Este aspecto es uno de los más importantes de la educación emocional.

4. Las relaciones interpersonales son una potencial fuente de conflictos en cualquier contexto de la vida social. Los conflictos afectan al mundo emocional y a veces son provocados por una inadecuada expresión de las emociones o un problema en la gestión de las mismas.

5. Desde la salud emocional: Recientes investigaciones de la neurociencia destacan la estrecha relación entre las emociones y la salud. Todos los estímulos que nos llegan producen una cierta tensión emocional, por ello el control del estrés es uno de los aspectos importantes que justifican esta necesidad de cambio.

Desarrollar este proyecto o idea, implica un compromiso firme entre todos los profesionales implicados en el proceso de enseñanza aprendizaje, para que nuestros futuros alumnos tengan un desarrollo integral de su persona, el desarrollo de un pensamiento crítico ante las situaciones y problemas que se les presenten, sepan gestionar los recursos disponibles con mayor eficacia y sepan disfrutar de las relaciones sociales, las cuales nos bridan una gran oportunidad de un conocimiento colectivo superior al individual. 
Objetivo: Dar a conocer la relevancia de la formación de los docentes en educación emocional independientemente de su ámbito de actuación.

\section{2.- METODO}

Muestra: 22 publicaciones de la bases de datos Dialnet las cuales se dividen en 17 artículos y 5 tesis doctorales, relacionadas con el estado de la educación emocional en la formación docente.

Comenzamos realizando una búsqueda bibliografía introduciendo los descriptores "Formación docente" y "Educación emocional”. Hemos creído oportuno que la muestra sea lo más representativa posible.

En el análisis de todas las publicaciones (17 artículos y 5 tesis doctorales) observamos que la mayoría perciben niveles muy bajos sobre la formación en educación emocional, independientemente del nivel académico. Sin embargo, vemos que las publicaciones que van dirigidas a la etapa universitaria (86.6\%) tiene un contenido más afectivo y más centrado en el carácter emocional, mientras que el 9\% de ellos se dirigen hacia la etapa de secundaria y 1 de ellos a educación infantil. Destacamos la existencia de un vacío en la etapa de primaria relacionado con la temática que estamos tratando. Hemos de resaltar la importancia que tiene este nivel educativo ya que son los cimientos que sustentan la formación de todos los individuos.

\section{Grafico 1.}

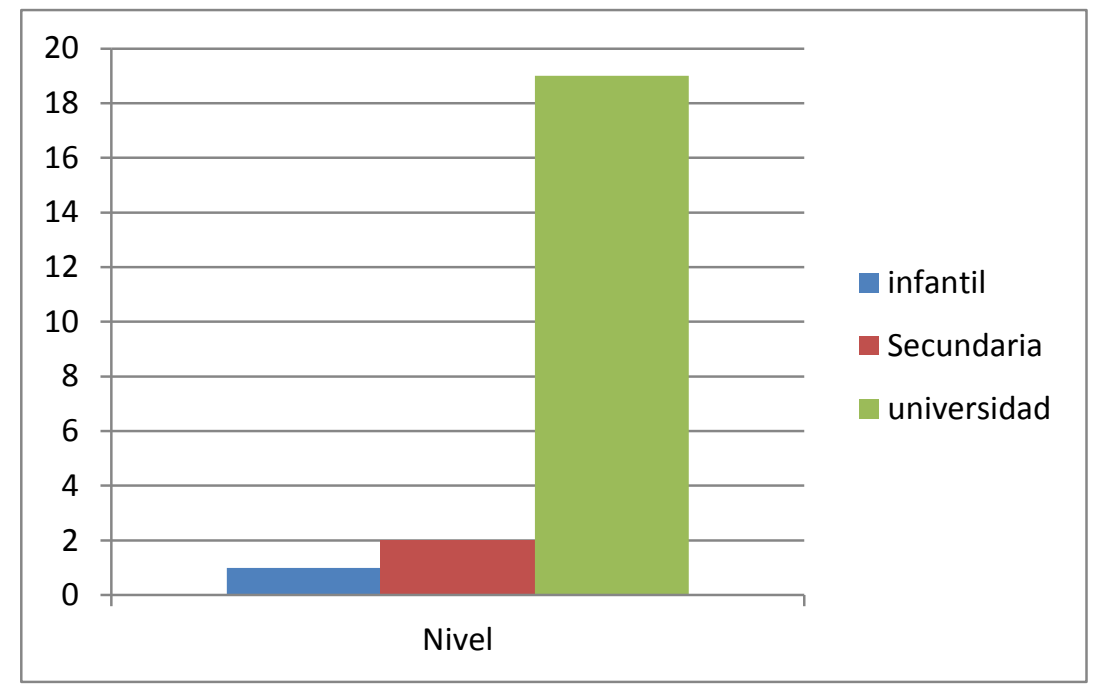

En cuanto al tipo de publicación vemos como hay un $60 \%$ de los documentos enfocados hacia la investigación, entendemos por ello que existe una preferencia por 
crear y mejorar nuevos conocimientos, que para aplicar o intervenir con aquellos ya existentes.

\section{Grafico 2}

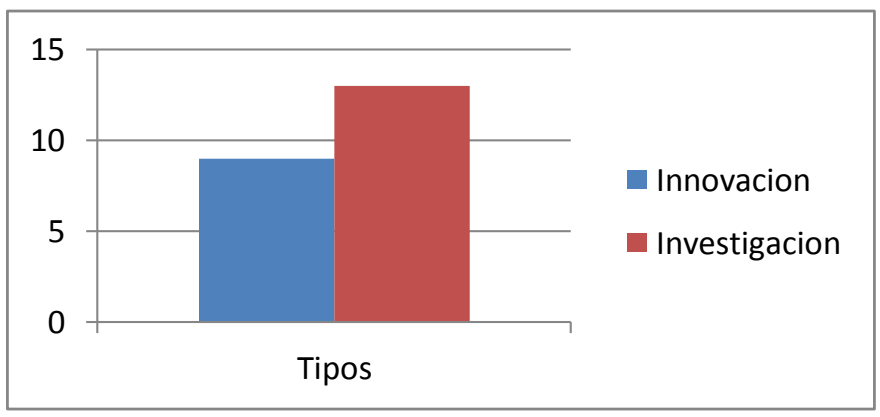

Con respecto a la formación del docente en educación emocional observamos una gran mayoría el 55\% relacionado con esta temática. Dejando las restantes centradas en las diferentes áreas de la educación; emociones en el área de matemáticas, en el teatro, inglés con carácter emocional, las emociones en el área de enfermería, etc.

Grafica 3

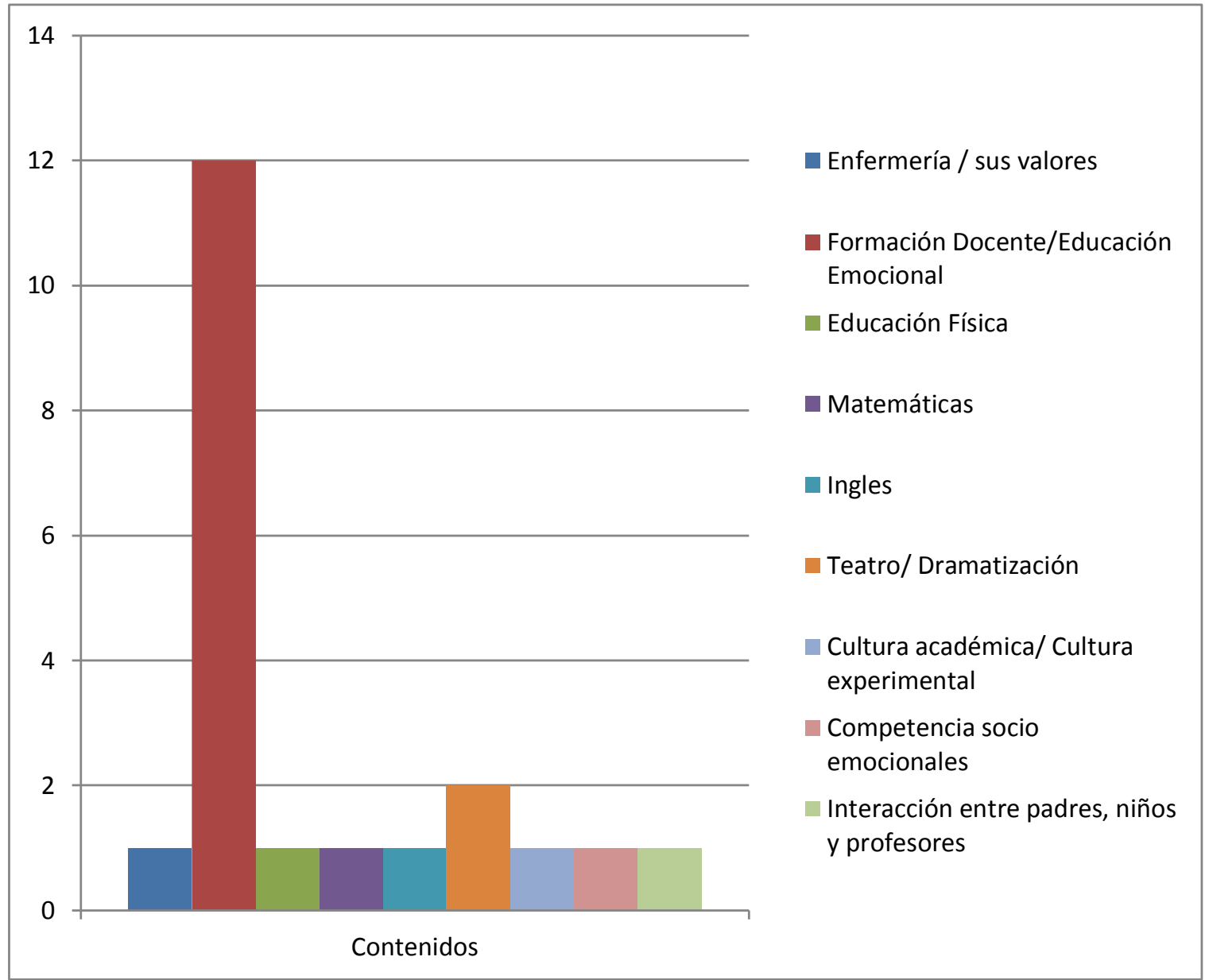


Observamos como las publicaciones existentes en Dialnet sobre esta temática presentan en su mayoría formato artículo. Por lo que podemos deducir que se no se ha profundizado lo suficiente ya que no existe un gran número de tesis doctorales.

Otro aspecto que cabe destacar, es la fecha de las publicaciones, en la que se ve que hay una clara actualidad sobre el tema en los que se refiere al formato artículo, sin embargo en las tesis podemos percibir un estancamiento en sus publicaciones.

\section{Grafico 4}

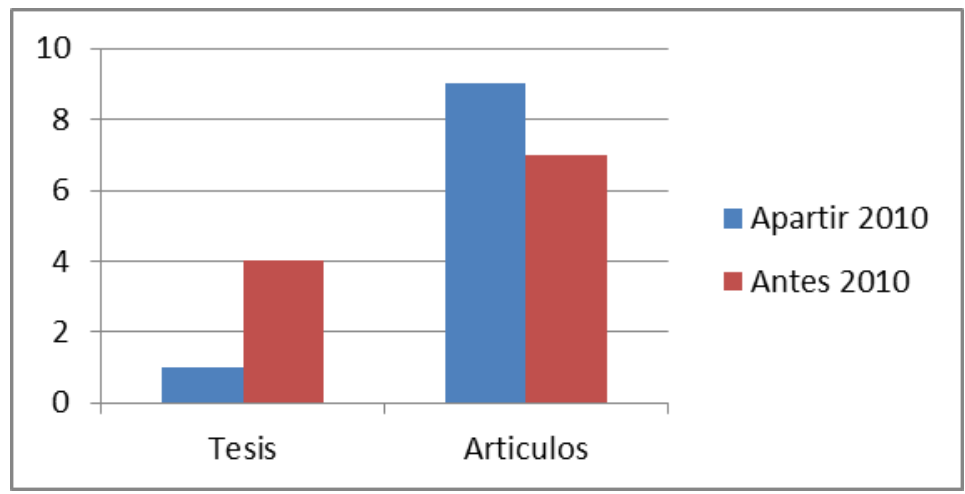

Además una revisión de la LOE nos muestra que no existe un apartado específico para las competencias emocionales y su desarrollo en la escuela, simplemente nombra la educación emocional como una de las competencias a desarrollar en el ámbito escolar.

Por la ausencia del carácter emocional en la formación de los docentes y futuros docentes no suelen afrontar en el aula los temas o bloques relacionados con la inteligencia emocional, gestión de las emociones y comprensión de las mismas, que es precisamente lo que la sociedad actual más demanda.

\section{3.- CONCLUSIÓN.}

En este estudio hemos realizado una exploración en la base de datos Dialnet, relacionado con la educación emocional en la formación docente, con el objetivo de dar a conocer la relevancia de la formación de los docentes en educación emocional independientemente de su ámbito de actuación. Podemos decir que la formación general en educación emocional es escasa y además cuenta con muy poca profundización e indagación en su desarrollo y aplicación en el aula. El aspecto más llamativo que hemos observado en la realización de este estudio es que existe un vacío en la formación 
docente en primaria el cual, es el nivel donde se sustenta la base del proceso educativo y donde se dan a conocer, se practican y se afianzan los conocimientos. Por ello se debe promocionar nuevas líneas de investigaciones enfocadas al nivel educativo de primaria.

Por ultimo señalar que en al ámbito de la educación física solo existe una publicación en formato artículo del año 2009, con lo que entendemos que no se ha reconocido la importancia que tiene este área educativa dentro del ámbito emocional, ya que es una asignatura que se caracteriza por un alto grado en las relaciones sociales de los alumnos, así como la predisposición de los mismo para enfrentar la materia, con lo que debemos aprovechar esta situación para promocionar nuevas investigaciones.

\section{4. - BIBLIOGRAFÍA.}

Bisquerra, R. (2000): Educación Emocional y bienestar. Barcelona: Praxis.

Bisquerra, R. (2005). La educación emocional en la formación del profesorado. Revista: Educación Emociona. Barcelona.

Bueno, C., Teruel, M., Valero, A. (2005). La inteligencia emocional en alumnos de magisterio percepción y comprensión. Educación emocional

Costa, M. (2002): Una asignatura pendiente en el perfil y currículo de los profesionales la competencia social. Jornadas de Habilidades sociales. Comunidad de Castilla. Valladolid.

Fernández-Berrocal, P.; Extremera, N. (2002): «La inteligencia emocional como una habilidad esencial en la escuela», en Revista Iberoamericana de Educación, 29, pp. 1-6.

Fernández-Berrocal, P.; Ramos, N. (2004): Desarrolla tu inteligencia emocional. Barcelona.

Fernández-Domínguez, M. R. (2005). La formación para el crecimiento y el desarrollo personal del profesorado. Revista Interuniversitaria de Formación del profesorado, 19, 195-251.

Filella, G., Ramona, R., Angulló, M., y Soldevila, A. (2002): Formación del profesorado: asesoramiento sobre educación emocional en centros escolares de infantil y primaria. Educar, 30, 159-167.

Sala, J. (2002). Ideas previas sobre la docencia y competencias emocionales en estudiantes de Ciencias de la Educación. Revista Española de Pedagogía, 223, 543-557.

Teruel, M. P. (2000). La inteligencia emocional en el currículo de la formación inicial de los maestros. Revista investigadora de Formación de Profesorado, 38, 141152. 